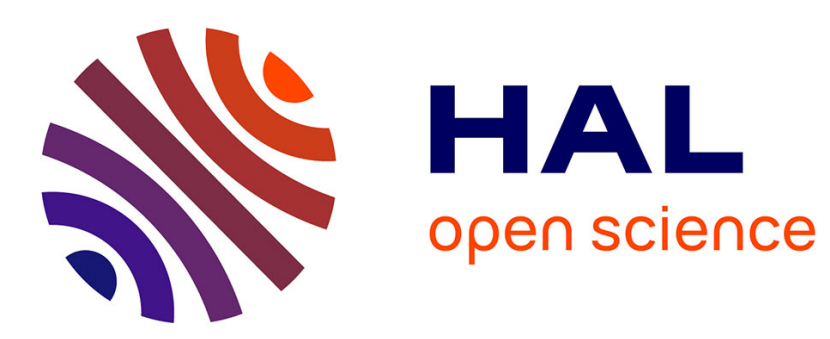

\title{
The bodily experience of disabled athletes. A phenomenological study of powerchair football
}

Rémi Richard, Eric Perera, Nathalie Le Roux

\section{To cite this version:}

Rémi Richard, Eric Perera, Nathalie Le Roux. The bodily experience of disabled athletes. A phenomenological study of powerchair football. Sport in Society, inPress, 10.1080/17430437.2019.1609948 . hal-02122804

\section{HAL Id: hal-02122804 \\ https://hal.umontpellier.fr/hal-02122804}

Submitted on 7 May 2019

HAL is a multi-disciplinary open access archive for the deposit and dissemination of scientific research documents, whether they are published or not. The documents may come from teaching and research institutions in France or abroad, or from public or private research centers.
L'archive ouverte pluridisciplinaire HAL, est destinée au dépôt et à la diffusion de documents scientifiques de niveau recherche, publiés ou non, émanant des établissements d'enseignement et de recherche français ou étrangers, des laboratoires publics ou privés. 


\title{
The bodily experience of disabled athletes. A phenomenological study of powerchair football
}

\author{
Remi Richard (D), Eric Perera and Nathalie Le Roux \\ UFr StApS, University of Montpellier, Montpellier, France
}

\begin{abstract}
Using Merleau-Ponty's propositions concerning phenomenology this paper aims to understand the physical experience of athletes using powerchairs. Powerchair football is an adapted team sport specifically conceived to be practiced by people who use powerchairs. To conduct this study, we carried out in-depth interviews with eight French powerchair football players. The results of this study show that modifications of the powerchair allow mutual adjustments between the powerchair and the individual. These modifications are prior to the embodiment process of the powerchair which takes place during the practice of sport. Results also evidence that embodying the powerchair in a sporting context offers the opportunity to reconnect with intentionality and contributes to the development of an athletic identity.
\end{abstract}

\section{KEYWORDS}

Phenomenology; disability; powerchair football; embodiment; sport

\section{Introduction}

Powerchair football, also called powersoccer, is an adapted sport with an increasing number of players, but is also curiously little-known by the general public. It is one of the two existing team-sports ${ }^{1}$ specifically conceived to be practiced by people who use powerchairs. This activity, which appeared in France in the 1970s (Jeffress 2015), was originally proposed within specialised centres for disabled children in order to offer a fun way of learning how to manoeuvre a powerchair. Powerchair football was brought to an international level through the creation of the FIPFA (Fédération Internationale de Powerchair Football Association) in 2006, and flourished to the point of numbering over 3500 players, from 27 different countries. ${ }^{2}$ This adapted sport pits two teams against each other on a field the size of a standard basketball court. Each team is composed of four players, both men and women, who use powered wheelchairs equipped with bumpers. A $33 \mathrm{~cm}$ diameter ball must go through the opponent's goal, composed of poles spaced $6 \mathrm{~m}$ apart. This sport has caught the attention of researchers: Wessel, Wentz, and Markel (2011), along with Jeffress and Brown(2017), studied its psycho-social benefits, while Cottingham, Pate, and Gearity (2015) examined 'inspiration' in the context of powerchair football tournaments. Richard, Joncheray, and Dugas (2015), as well as Cottingham et al. (2018), investigated the construction of gender within it. The health and wellness benefits of powerchair football (Barfield et al. 
2005; Barfield and Malone 2013; Barfield, Newsone, and Malone 2016; Senk 2017), as well as the improvement it brings in the ability to handle a powerchair (Kumar et al. 2012) have also been demonstrated. We propose to use a phenomenological outlook (Merleau-Ponty 1945) on the bodily experience of these athletes. Indeed, this article examines the process of wheelchair embodiment by athletes who are considered as being 'severely' disabled, during powerchair football practice, and the identity issues linked to it.

\section{Theoretical framework}

We will start by defining the concept of phenomenal body developed by Merleau-Ponty (1945) in order to appreciate its importance in the field of sports. Then, we will detail the contribution of phenomenology in documenting the corporeal experience of disabled people, as well as its utility in understanding disabled sports practices.

\section{Phenomenology, body and movement}

Human experience is fundamentally embodied (Zeiler 2010). The concept of the phenomenal body (Lapointe 1971) is the keystone of the phenomenological approach described by Merleau-Ponty. Indeed, the latter emphasised the indefectible unity constituted by the person, their body and their 'world': 'It is through my body that I understand other people, just as it is through my body that I perceive "things"" (Merleau-Ponty 1945, 216). The corporeal experience is the starting point for understanding the world. The phenomenal body, as described by Merleau-Ponty, has three fundamental properties: it is a moving, sensitive and 'intentional' body. The phenomenal body is a moving body, because the movement will shed light on a dark world. As explained by Merleau-Ponty (1945, 97): 'If it is true that I am conscious of my body via the world, that it is the unperceived term in the centre of the world towards which all objects turn their face, it is true for the same reason that my body is the pivot of the world'. The experienced body is thus an instance of movement, and my point of view on the world depends on my position in space. By a very same movement, the body appears to the incarnated individual and appears to the world, and the body answers to the world through its movement (Aggerholm and Højbjerre Larsen 2017). Through perception, individuals feel their body and their world as belonging to them. Merleau-Ponty (1945) used the concept of 'being-in the world' to explain that the world is, above all, that of individuals who has their own way of perceiving and filling the space around them. We live the body and the world concomitantly; in the same way as the body and the mind are inseparable, the body and the world constitute a system (Abrams 2015). Incarnated consciousness is the condition itself of 'being-in-the-world'. In this process, physical practices hold a central position: the sporting body is 'in essence' a phenomenal body. Sporting activities engage an individual in an intense sensory experience of their body (Aggerholm and Højbjerre Larsen 2017; Allen-Collinson 2009; Allen-Collinson and Hockey 2011; Brymer and Schweitzer 2017), so they are ideal situations in which to perform phenomenological analyses. Engaging the body in sporting movements leads to the emergence of specific sensory-motor experiences. As it was explained by Hockey and Collinson $(2007,123)$ 'Sportspeople thus touch, and are in turn touched, by the physical properties of the terrain and equipment, and so build a two-way, embodied relationship with them'. 
In the face of the great value that a phenomenological analysis of sports would represent, Hockey and Collinson (2007) note the lack of studies which are devoted to it.

\section{Phenomenology and experiencing a disabled body}

Despite the limited initial attention given to the issue of corporeal experience by disability studies, the question of embodiment has taken on a more central place since the $1990 \mathrm{~s}$ (Garland-Thomson 2005, 2013; Murphy 1990; Papadimitriou 2012; Seymour 1998; Turner 2001; Zitzelsberger 2005). Disability leads to a profound disruption in the dynamic relationship between the person and the world, a relationship that is often invisible in the case of a non-disabled person (Leder 1990). Experiencing environmental obstacles, oppression, pain (whether it be biological or social), ${ }^{3}$ leads to a dys-appearance (Leder 1990). Paterson and Hughes $(1999,603)$ explained that 'the body becomes unceasingly present in experience, albeit in an alien and dysfunctional manner'. Essays that relate the corporeal experience lived by people who were affected in their motor skills highlight these issues raised by the phenomenology of disabled bodies. The narratives of disabled people attest of a phenomenon in which there is a distancing from the body (Abrams 2015), used as a 'strategy' of personal protection, that often occurs. Robert Murphy, an anthropologist who became progressively quadriplegic, detailed this situation: 'From an emotional point of view, I have somewhat detached myself from my body; I only ever really refer to one of my members as the leg or the arm now' (1990, 143). Nuss (2011, 32), an essayist and French activist with spinal muscular atrophy, spoke more openly of his disembodiment efforts: 'In reality, I had disembodied myself in order to live, even to survive. This is a terrible and touching realisation which shows the long path to leaving, escaping, the disembodiment which served me as a shield, as an armour'. This process of disembodiment is particularly intense during 'critical' times. Thus Murphy (1990, 44, 45) describes his first experience of disembodiment when his illness was announced: 'everything happened as if the real me was standing right there, watching what was happening to somebody else. [...] It wasn't bravery, only a manifestation of the "disembodied me" which would go on to strongly reaffirm itself during the years of disability to come'.

In a similar way, Parisot $(2010,147)$, affected by muscular dystrophy, explained what took place during healthcare visits: 'During the one and a half hour of my nursing care, I live a kind of disembodiment: I set aside what I am, my self-esteem, my affinities, my personality, and I become someone else, when someone else is taking care of my body. My mind flies away, and I abandon my body to them'. At this point, we can see a parallel with the work of Leder on dys-appearance. While the body is rendered invisible, silent, in an everyday sense, Leder (1990) pointed out that its dysfunction made it 'resurge'. He explained that the 'dys-appearance' is like the body's resurgence, 'but precisely in a dys-state' (Leder 1990, 84). In the cases described above, dys-appearance is not directly related to a 'dys-state', but rather to a loss of control over one's own body. To face it, disembodiment appears as the most obvious protection of one's identity (Paterson and Hughes 1999). By abandoning a body that is a 'source of illbeing' (Mehta 2011), the individual establishes a dualist posture (Abrams 2015). However, for all the authors mentioned above, disembodiment leads to a loss of self-concept. Marcel Nuss $(2011,32)$ explained that 'without my body I am not, nor anybody for that matter. Whether or not we like our body, it is ours'. Parisot (2010) explains 
that her daily practices of "disembodiment" give her a feeling of scission and loss of identity. Murphy $(1990,149)$ affirmed that although his impression of embodiment was self-evident and unconscious, his impression of disembodiment became 'a problem, negative - and conscious. My identity has lost its tethers, it has become contingent and dependent on a physical impairment'. Disembodied individuals constitute a phenomenological nonsense: individuals are embodied, in the same way as their "being-in-the-world" and therefore their identity (Merleau-Ponty 1945). To deny one's embodied condition is an unbearable situation of self-refusal. As outlined by Abrams $(2015,121)$ 'Cartesianism does not reflect the human way of being. Embodiment does'.

However, positive sensory-motor experience constitutes, for Parisot (2010), Nuss (2011), and Murphy (1990), a path leading to the rehabilitation of self (Apelmo 2016; Dyck and Archetti 2003). Thus it would appear that any act, every gesture, each movement or sensation enables the person to 'reconnect' with their corporeality. According to Parisot $(2010,149)$ :

There are, probably, thousands of ways to "recapture" the body. For instance, I was able to recover the long lost sensation of swimming in the sea. Specially conceived beach chairs, using floats, enable one to bathe in security while staying seated. [...]. What is interesting is to leave everyday sensations behind, those of the flat surface when you are sitting and moving on four wheels, in order to access a three-dimensional sensation.

The phenomenological analysis conducted by Apelmo (2016) among wheelchair athletes highlighted this process. Providing 'bodily pleasure and strength' (Apelmo 2016, 88), the practice of sport allows to reconnect with one's body. Adapted sports both provide people with positive experiences of connecting with their bodies and contribute to changing their body image and schema (Aggerholm and Moltke Martiny 2017; Belo and Mendes 2017). The sporting experience, if not centred on ableist conceptions (Giese and Ruin 2018; Howe 2018), allows a form of empowerment for people with "severe impairments" (Silva and Howe 2018). This sporting experience brings psychosocial benefits: it contributes to the construction of a positive identity (Pack, Kelly and Arvinen-Barrow 2017; Schipper, Lieberman and Moody 2017) and to a multiplication of social relationships (Aggerholm and Moltke Martiny 2017; Apelmo 2016; Jeffress and Brown 2017; Marcellini, 2005).

In light of these studies, we can legitimately question the specificity of the bodily experience of athletes who use a powerchair. The objective of this paper is to understand the bodily experience by analysing the processes of embodiment that powerchair football generates. We will demonstrate that the "being in the world" of the powerchair football player is characterised by an intense embodiment of the powerchair and by the construction of a positive athletic identity.

\section{Method}

The elements presented here are part of a wider research project on powerchair football in France, conducted between 2010 and 2013 (Richard 2017). For the present paper we will focus more specifically on studying the body experience of eight French powerchair football players. In order to highlight this corporeal experience, we conducted a phenomenological interpretative analysis of the first-person speeches of these players. This analytical method is particularly suitable for capturing the sense and meaning that individuals give to their practice (Sparkes and Smith 2014). 


\section{Participants}

The sample included two women and six men whose ages ranged from 23 to 35, with an average age of 30. All participants had to be regular athletes: playing powerchair football for more than three years, participating in at least one training session every week and regularly participating in tournaments. The education assistant position occupied by a researcher in a school providing powerchair football made it possible to identify players with the profile sought by network sampling. As far as possible, we ensured maximum variation in our sample with respect to gender and impairment. Choosing to select experienced participants resulted in a significant amount of quality information. As Smith and Osborn $(2015,56)$ explained, this choice of a small sample of experienced people ensures 'a detailed interpretative account of the casesincluded'.

\section{Instrument}

To examine the body experience of powerchair football players, we conducted interviews following the explanation method developed by Vermersch $(2005,2009)$. The purpose of the explanation interview is to obtain a detailed and precise description of the subjective experience. The objective is not to identify the reasons for the action (the why) but to assess the ways in which people experience situations (the how) and the meaning they attribute to them (Petitmengin 2006). It gives access to the lived dimensions of action that are not necessarily immediately conscious (Vermersch 2005; Petitmengin, 2006). In order to create the right conditions for interviewees to report as accurately as possible on their subjectivity (Vermersch 2009), the researcher can rely on photographs (Mouchet, Morgan, and Thomas 2018; Orr and Phoenix 2015) or videos (Merchant 2011) of the experience in question.

To conduct interviews, we used video clips of the participant's match recorded a few days before the meeting. During the interview, we watched the videos and asked the player to make as accurate and thorough a description as possible. Then, the second part of the interview provided biographical information on the athlete's trajectory and her or his more general sporting experience. These in-depth interviews were conducted between June 2012 and February 2013 at the players' homes. All interviews were conducted in French and then translated. Their duration was between $1 \mathrm{~h} 30$ and $3 \mathrm{~h}$ and they were sometimes repeated if necessary. The recordings were fully transcribed to form a corpus of 218 pages of verbatim. Discussions with players outside the interviews, recorded in a field notebook, also reinforce the study.

Table 1. presentation of the interviewees.

\begin{tabular}{llc}
\hline name/Gender & \multicolumn{1}{c}{$\begin{array}{c}\text { Age (at } \\
\text { powerchair football practice }\end{array}$} & $\begin{array}{c}\text { the } \\
\text { of the } \\
\text { interview) }\end{array}$ \\
\hline Abdel Male & Started playing powerchair football at the age of 13 & 35 \\
Amélie Female & Started playing powerchair football at the age of 14 & 30 \\
Aymeric Male & Started playing powerchair football at the age of 10 & 26 \\
Damien Male & Started playing powerchair football at the age of 13 & 35 \\
Loïc Male & Started playing powerchair football at the age of 9 & 23 \\
romain Male & Started playing powerchair football at the age of 16 & 32 \\
Salim Male & Started playing powerchair football at the age of 13 & 28 \\
SoniaFemale & Started playing powerchair football at the age of 17 & 32 \\
\hline
\end{tabular}




\section{Procedure}

All participants were over 18 years old at the time of the interview and the names used in this article were changed. They were informed before each interview of the nature of the study and gave their informed consent. The authors were not required to go through an institutional review board (IRB) to approve this research.

We conducted a phenomenological interpretive analysis of the data. A first reading allowed researchers to familiarise themselves with the content of the interviews. This first reading also made it possible to annotate the text in order to establish an 'exploratory coding' of the data (Sparkes and Smith 2014, 127). A second reading identified and labelled the themes of the corpus. Based on the notes of the first phase, we reformulated the content of each section of the text using academic terminology. The third step of the analysis consisted in establishing a list of the themes identified in each interview to identify connections between them. It is at this stage that the structure of the analysis took shape (Sparkes and Smith 2014). This step also involved prioritising the themes (main themes and subordinate concepts). Then, we reorganised and listed the themes in a table. A table was drawn up for each interview. The last step 'involves looking for patterns across cases' (Sparkes and Smith $2014,129)$. Using the tables, we put the interviews into perspective by identifying recurring or unique themes and assessed the extent to which the testimonies of each participant were different or similar. This last step allowed the creation of a unique table and to identify the three main themes presented in this article.

\section{Results and discussion}

Data analysis highlighted three themes that characterised the athletes' body experience: (i) the modification brought to the wheelchair, (ii) the embodiment processes and (iii) the identity issues linked to powerchair football participation.

\section{Modifying one's wheelchair, a prerequisite for embodiment}

All the players interviewed stressed the importance of modifying their powerchairs. Indeed, players make significant efforts to transform their powerchairs into sporting tools. These modifications are necessary for embodiment, that is, to integrate it fully into the body schema. It is important to remember that, basically, powerchairs are medical tools for rehabilitation (Watson and Woods 2005). They share similarities with other orthopaedic materials such as splints or corsets. Assimilating a wheelchair, an almost paradigmatic symbol of physical disability (Marcellini, De Léséleuc, and Le Roux 2008; Watson and Woods 2005), to a piece of sports equipment is not an easy task. This is even more complicated when it comes to a powerchair, a technology that is almost never associated with sports (Howe and Silva 2017). Thus, players apply a plethora of strategies to transform the powered wheelchair into a sports instrument.

The first strategy, the most obvious one, consists in customising the standard wheelchair by bringing aesthetic modifications and dressing it to make it more personal. The reason behind this customisation is to hide the chair's trademark. Indeed, in France, at the time of the research (in 2012 and 2013), almost all the players had the same model of powered wheelchair, produced by a renowned manufacturer of medicalequipment. 
Most of the time, the players changed the colours of their powerchair to those of the 'nondisabled' soccer team they were rooting for. Sometimes, they used stickers of famous soccer clubs or those of branded sports equipment manufacturers. ${ }^{4}$ As Sonia explained:

I don't want my chair to look too "disability”, so I put some [she mentions a sports equipment manufacturer's brand] stickers on top of those of the powerchair's brand'. Interview with Sonia.

The aim of these customisations was twofold. First, removing the medical manufacturer's brand was a way of challenging the medicalisation of disability. Then, these customisations had an aesthetic dimension: they helped to personalise the powerchair and to turn it into a sporting instrument.

Another strategy, less visible but also important, consisted in modifying the wheelchair, 'tinkering' with it in order to increase its sporting performances. Watson and Woods (2008) emphasised the efforts made by athletes who use manual wheelchairs to increase their performances. Interviewed athletes reported similar efforts. For example, a player exchanged his front wheels, after having judged them as being too wide. Thinner scooter wheels are, according to him, more advantageous during duels and more sensitive for rotation purposes. However, after this type of modification, powered wheelchairs are no longer fit for outdoor use.

Finally, modifying the powerchair also meant changing its speed parameters (Kumar et al. 2012). A standard powerchair offers various speed programs (five in total) which the users can adapt to their convenience. The powerchair football rules impose a forward and reverse speed limit of $10 \mathrm{~km} / \mathrm{h}$, but other parameters are left free to adjust. Using a specific modulating box, the athlete can therefore change these parameters in order to make the powerchair more or less responsive. The players can thus modify turn speeds, torque and control delay. These adjustments, already observed by Jeffress (2015), fully participated in the embodiment process of the powerchair:

You have to progress with your powerchair. Go up step by step. And sometimes you'll be much more efficient with less sensitive parameters. There is an interaction between the machine and the man, I think. Interview with Salim.

This adjustment process highlights the mutual adaptation engaged in powerchair football practice. In her research on interactions between people with neuromuscular diseases and their wheelchairs, Winance (2000), described a process of adaptation which mainly consisted in 'modifying the prosthesis and positioning the person in order to make him/her feel at ease and for the action to be passed from one to the other' (Winance 2000, 14). In the case of the interviewed powerchairfootball players, we were able to observe adjustment situations of a very subtle nature:

We modified the spring of the joystick. It's to make it more sensitive. We also changed the armrests. Originally, it was these (he shows me the armrests on a powered wheelchair for daily use). Instead, we mounted some thin armrests from a manual wheelchair...it's better, and it makes the chair lighter. We also modified my position in the chair to lean further back. Because, the more I lean back, the more power I have for rotations. Interview with Loïc.

In addition to these modifications, which we could call 'material', we must also point out the central role played by the narratives in wheelchair embodiment. Indeed, it is the performative character (Butler 2006) of speech which, at the same time as it describes the wheelchair, takes part in transforming it (through representations) into a sporting 
instrument. In fact, very regularly, when designating their wheelchair, the players used sporting metaphors. Sometimes, the players used the behavioral characteristics of athletes in order to describe their wheelchair: it can be hardy, nervous, or powerful. On other occasions, the chair was compared to sporting equipment. For instance, a player explained to us why he would not go outside with his soccer powerchair:

When you finish a football match, you don't go walking on the tarmac in your studded soccer shoes...well, for me, it's the same, my wheelchair is my soccer boots. I'm not going to go and damage it by going outside with it. Discussion with Damien.

Furthermore, some players no longer made a distinction between their body and their wheelchair. For instance, a player would say 'I'm overheated' when the temperature of the motor on his wheelchair was too high to continue playing. As Winance $(2006,58)$ demonstrated, a true work of 'emotional adjustment' takes place which 'makes possible the emergence of a common materiality'. This redefining of the 'material' limits of the body was sometimes spontaneously brought up by the players during the interviews. The following exchange with Romain illustrates how the lines between the body and the powerchair are blurred:

When you're playing soccer, never do you say to yourself: it's the wheelchair! The chair is a part of you.

Researcher: Do you mean to say that it's a little like a car?

No, it goes further than that, because...because, somehow you, you know...It's like saying that a soccer players left the pitch without their legs. They don't leave their legs! They uses their legs to go to the library, they knows them better than pilots know their car. Inevitably. A car, it'll always remain an outdoor thing, in the end they'll leave their car. But us, our wheelchair, we have it every day, it's like our legs. Interview with Romain.

These words concerning the body lead us to think that the powerchair cannot be seen as a simple tool for sports which would remain 'outside': the chair becomes, through these words, a part of the body, in the same way as an arm or a leg. Because, through movement, an embodiment process of the wheelchair takesplace.

\section{The chair's embodiment}

Papadimitriou (2008) and Winance (2006) demonstrated the central role played by the wheelchair's embodiment in rehabilitating patients with spinal cord injury. While interviewing powerchair football players, we realised that a form of hybridisation (Andrieu 2008) between the body and the chair took place, leading to an efficient mobility: they mingle in, and through, the physical action. This hybridisation engages the disabled athlete in a new field of bodily experiences (Winance 2006), the technology becomes enabling (Pavey, Warren, and Allen-Collinson 2015). During our interviews, we realised how difficult it was for the players to put their experience of the wheelchair's embodiment 'into words'. Speaking of physical experiences is not self-evident; it is an exercise which takes time. At the beginning of the interviews, the players evoked these sensations without actually being able to describe them: 
It's true that you feel...They're feelings that are a bit hard to describe. It's a kind of chemistry, but there are things that happen during the football match... There are things... There are sensations.... Interview with Abdel.

Indeed, the players tended to report 'bizarre' or 'inexplicable' sensations. Progressively, during the course of the interview, and especially when we broached or watched specific technical movements, the description of the bodily experience was triggered. The explicitation of the phase of control of the ball, which demands a singular proprioceptive attention, was particularly useful for exposing this chemistry which takes place between the movement, the player and the wheelchair.

I can feel the vibration. And, depending on the sound and on the vibration, I know whether the ball has touched the wheel or the rim. And depending on this, the rebound will be different. And even, to go further into details, the ball can touch the anti-tipper. If it touches it, the ball is not ejected back. In fact, what generally happens is that it'll slow down a bit, and then it's over. It's not even the kind of "screwing up" that you can rectify, it's completely over. The ball stays under your feet. Interview with Abdel.

In describing his experience when controlling the ball, the player exposed this embodiment of the powerchair's dynamics. By using the powerchair, the body becomes a sensitive set; it mingles with 'the world' via the sensory-motor experience. Abdel explained that he could feel through his powerchair, 'like a blind person sees the world through the white stick'.

The moment he hits the ball is a phase during which the athlete's 'being-in-the-world' is intensified:

\begin{abstract}
Ah, you can feel it really really well. In fact, hum...after a while, you know your chair well, really well, you even know the weight of the ball, without lifting it...you know the weight of the ball. Alright, so for the weight, it's not precise ...You're not going to say that it weighs $2 \mathrm{~kg}$ $400 \mathrm{~g}$... But you know, depending on how it's going to bounce back, depending on the intensity you put into your hitting movement, on how the ball reacts, well you know whether it's heavy or not. Depending on the impact on your wheelchair when the ball arrives quickly, you know whether it's heavy or not. You know it because you feel it. You feel the vibrations, you feel it in your back, in the backrest, in your limbs, in your hand, even if you're para or tetra, you feel the ball's impact, you feel the vibrations. Interview with Abdel.
\end{abstract}

The perceptual activity engages a certain set of elements which cannot be dissociated. For Amélie, to feel the ball is the result of a process in which the body, the powerchair and the ball, are completely indivisible:

But maybe that, to focus all your attention on the ball, is a way of feeling it...Do you see what I mean? Since you're really focused on it, and that your wheelchair is under your control for placing it over here or over there, maybe it's also a way of feeling it! Of feeling it differently! Can you see what I mean? [...] You can feel your wheelchair, you can feel impacts with the others, lot of things. All this, it can’t be dissociated. Interview with Amélie.

All the interviews revealed the extent to which powerchair football engages the players with a particular attention to their 'being-in-the-world'. Powerchair football trains the athlete toward a 'body awareness' which not only includes the powerchair (Papadimitriou 2008, 697), but also the ball, and even the other players. 
In addition to this, they showed that the proprioceptive elements described varied depending on the person and their disability. Damien, for instance, who controlled his wheelchair with his chin, seemed to pay a particular attention to the resonance phenomenon.

But anyway, me, I feel it when the ball bounces too hard. When it's behind me, I feel the ball.

Researcher: How do you feel it?

In my head! And believe me, when you receive a powerful shoot...like "bam" in the bumper, well, it's not like being hit, but you do get a little jolt. Ha, see... and it resonates a little. At least for me it does! I don't know what it's like for the others. Just because I don't see the ball doesn't mean I don't see where it is. I guess.

Researcher: Yes, other players told me the same thing. Some of them told me that they felt it through the hand.

No, for me it's mainly through the chin. Interview with Damien.

Little by little, through repeating and diversifying motor experiences, individuals can modify their body schema: not only will they appropriate the effects that their body may have on their surroundings, but also and more importantly, they will embody the equipment's dynamics and become 'enwheeled' (Papadimitriou 2008). Warnier (1999), using the works of Merleau-Ponty (1945) and Schilder (1968), evidenced the capacity of individuals to 'embody the dynamics of objects'. This invisible process consists in modifying one's body schema, through physical movement and through perceptual and proprioceptive activity, in order for it to integrate the material environment (Schilder 1968). The discourses reveal this expansion process of the player's body schema, encompassing the powered wheelchair (Schilder 1968).

In the athletes' speeches, the distinction between body and powered wheelchair collapsed. The players 'felt' the world through the chair as a part of their body. This phenomenon thus brought us to rethink the limits of corporeal materiality. Embodying the wheelchair opened the individual to new possibilities (Watson and Woods, 2005). As it was explained by Papadimitriou (2008, 699): 'acting from the body/chair constitutes re-embodiment: making the chair a part of one's body schema reconstructs the person's embodied capabilities'.

Comprehensively listening to the players allowed us to reveal the powerchair's embodiment process, but also the identity issues that it involved.

\section{Intentionality and athletic identity}

We showed that playing soccer leads to an embodiment of the powerchair. We will now underline how this phenomenon also engages the person in a field of new bodily possibilities, as well as the identity changes that this implies. We aim to support the idea that these subjectivities are strongly correlated to the 'sporting' activation of the body/chair, which enables the player to recreate the severely weakened link between movement and intention. Intention and projects are the direct link between phenomenology of the bodily experience and transforming one's 'being-in-the-world': 'From a phenomenological point of view, the world becomes embodied because it is our 'projects' that make it what it is' (Paterson and Hughes 1999, 603). 
The disabled body, which is often perceived or felt as being passive (Ahmed 2010; Apelmo 2016), will become, through and by the physical movement, an intentional and efficient body:

We live in a society where we are not perceived as productive, not 'really' productive... But all of a sudden, when you take part in a team sport, you are active, you do something, you score a goal, you help your team win. You are a defending player, you try and stop goals, you take part in a collective action, you create something...And all of a sudden, the image you have of yourself, and of your partners, changes. And so, it helps you build yourself, as a human being, as the maker of something. You build a result, you win, you lose.... Interview with Aymeric.

The physical action builds and represents a 'productive' individual, that is, an active and creative one. It offers disabled athletes an opportunity to physically activate their body alongside their intention in order to reach theirgoal.

And when you win, well, it shows to yourself that you can be useful. You're not useless... And besides the fact that it's just a football match, that it won't change the face of the world, for you it makes a difference... in your everyday life, you win a match, you come back stronger. Interview with Romain.

Moreover, this phenomenon is even stronger in the case of powerchair football, a situation in which embodying the powered wheelchair opens an entirely new field of sporting experiences. The chair is no longer used only to (re)acquire mobility, to make up for an 'impairment' or a 'disability', but is embodied to express the individual's aptitude and to underline a potential. Abdel's first memories of a powered wheelchair revealed these new capabilities:

Ok, the powered wheelchair is the image of disability, but there you are, you're going to be able to play powerchair football! And that, buddy, is completely different... because the powerchair, it goes at $10 \mathrm{~km} / \mathrm{h}$, and in the school playground, that's more efficient than "the standers". Then, you can dodge anything, it's like “waouh, you're moving!". Interview with Abdel.

The 'enwheeled' body, often perceived as a paradigmatic symbol of disability, becomes the source of a new experience, of a new relationship with the world. Papadimitriou (2008, 698) showed that 'being active and engaged constitutes a starting point for restructuring new abilities and ways of acting in the world as a person with a disability, as a newly abled adult'. At this point, we can see a parallel with our own observations: for our informers, being the actor of your own movement is the basis for building a sporting identity.

You play powerchair football, there it is! You become active. And the wheelchair is no longer the symbol of a worsening disability but a synonym for physical performance. You become efficient. You are the one who is efficient. Do you see what I mean? You decide to take it there, to do so... The fact that you are mastering it, you're the one doing this, you're the one who goes to the ball, do you see? It's...There it is, it's your own thing. Interview with Sonia.

Our results echoed those of Barfield and Malone (2013), Wessel et al. (2011) and Jeffress and Brown $(2017,247)$ who showed how powerchair football players 'gain significant benefits to their self-efficacy beliefs'.

The interviews also evidenced the fact that the feeling of being a 'true athlete' grew stronger when the competitive stakes were higher. This is coherent with the observations made by Huang and Brittain (2006) or Jeffress (2015), who showed that the competitive 
aspects of an activity push the question of disability into the background. While gaming, what matters is the performance of the person. The individual is an efficient, or not, athlete before being a 'disabled' person:

Well, the pressure, the stress of the competition, the...let's say...the collective aspect. The collective aspect of the sport. I mean... we play one for the other ... There's no more disability. On the pitch, it's a place... it's a place of freedom somehow, which you don't find elsewhere. And you're not going to be judged because you've got this or that disability. You will be judged because you scored a beautiful goal, or because you missed out on an action. Interview with Romain.

Although this is true for any level of practicing, it is even more so for 'high level' practice.

It's quite something to be on the national [French] team! When you're there, well, "you're the best in the world", all the other players look at you with shining eyes. When they look at you, you can see that it's not the same look. It's obvious. When you're on the national team, and when you're no longer anymore, it's not the same look. Even if, concretely, you are still the same person. It's the perception of others that changes. And it's true that sometimes, it helps you feel a little bit stronger. Interview with Salim.

Practicing powerchair football allows so-called 'severely disabled' people to embody sports values (Shilling 2016): performance, speed, overcoming your limits. There is an embodiment of values which are accessed through the activation of movement in a prosthetic body. The powerchair embodiment is the condition, and the vector, through which the individual built a sporting identity.

\section{Conclusion}

Using a phenomenological approach, the aim of this paper was to examine the bodily experiences of powerchair football players. More precisely, we sought to highlight the embodiment processes of the powerchair, which are initiated by sport practice, and to understand its consequences on identity. We were able to demonstrate that powerchair football engages the individual in a particular relationship with the wheelchair: the powerchair is first deeply modified in a quest for efficiency. The finer description of the athletes' bodily experience shed light on the wheelchair's embodiment processes. In this sense, powerchair football plays a part in reconfigurating the 'being-in-the-world' (MerleauPonty 1945).

We also showed that the sporting experience could truly constitute a place where subjectivation processes are at play, allowing to build and transform the athlete's identity. The

'enwheeled' football player rediscovers intentionality and the wheelchair's embodiment produces an active individual, both the decider and the author of her or his sporting actions.

This research was guided by the desire to highlight a sports population that is not sufficiently visible. The phenomenological analysis of powerchair football reveals the dynamic that exists between the embodiment processes of technologies and the reduction of the disability-related stigma. The sporting involvement of the prosthetic body makes it possible to deconstruct the stigmatizing stereotypes of passivity, weakness or uselessness still too often associated with the so-called "severe" disability.

Our research included a small group of participants and the aim here was not to generalise our observations to an entire population. To better understand these processes it is important to continue the phenomenological investigation of the body experience of athletes 
using a powerchair. Boccia or powerchair hockey, for example, are two unknown practices that would require more attention from scholars. Our study is also an invitation to pay particular attention to disabled athletes' bodily experiences and induces us to lay a different eye on disability. Leaving behind the ableist point of view, which considers disability to be a burden for physical activity (Campbell 2009), the attentive study of the experiences lived by these athletes leads us, on the contrary, to consider disability as a point on which to base new sporting subjectivities.

\section{Notes}

1. Along with Powerchair Hockey: http://powerchairhockey.org/

2. Fédération Internationale de Powerchair Football Association [International federation of powerchair football association]. Available at:http://fipfa.org.

3. 'One can argue that all pain is subjectively and, therefore, culturally meaningful. There is no pain that is exclusively biological. Pain always has meaning, is always 'socially informed' and it informs the social. Thus, pain should not be regarded as physical sensation with additions of meaning, but as permeated with meaning, permeated with culture and as a state of embodiment which 'produces culture' (Paterson and Hughes 1999, p. 603).

4. There is no objective of sponsorship and athletes do not receive any corporate royalties.

\section{ORCID}

Remi Richard (D) http://orcid.org/0000-0002-6170-367X

\section{References}

Abrams, T. 2015. "Cartesian Dualism and Disabled Phenomenology." Scandinavian Journal of Disability Research 18 (2): 128-188.

Aggerholm, K., and S. Højbjerre Larsen. 2017. "Parkour as Acrobatics. An Existential Phenomenological Study of Movement in Parkour." Qualitative Research in Sport, Exercise and Health 9 (1): 69-86. doi:10.1080/2159676X.2016.1196387.

Aggerholm, K., and K. M. Moltke Martiny. 2017. "Yes We Can! a Phenomenological Study of a Sports Camp for Young People with Cerebral Palsy." Adapted Physical Activity Quarterly 34 (4): 362-381. doi:10.1123/apaq.2015-0135

Ahmed, S. 2010. The Promise of Happiness. Durham, NC: Duke University Press. Allen-Collinson, J., and J. Hockey. 2007. "Grasping the Phenomenology of Sporting Bodies."

International Review for the Sociology of Sport 42 (2): 115-131. doi:10.1177/1012690207084747 Allen-Collinson, J. 2009. "Sporting Embodiment: Sports Studies and the (Continuing) Promise of Phenomenology." Qualitative Research in Sport E Exercise 1 (3): 279-296.

Allen-Collinson, J., and J. Hockey. 2011. "Feeling the Way: Notes toward a Haptic Phenomenology of Scuba Diving and Distance Running." International Review for the Sociology of Sport 46 (3): 330-345. doi:10.1177/1012690210380577

Andrieu, B. 2008. Devenir Hybride. Nancy: Presses Universitaires de Nancy.

Apelmo, E. 2016. Sport and the Female Disabled Body. London: Routledge.

Barfield, J. P., and L. A. Malone. 2013. "Perceived Exercise Benefits and Barriers among Power Wheelchair Soccer Players." The Journal of Rehabilitation Research and Development 50 (2): 231238. doi:10.1682/JRRD.2011.12.0234

Barfield, J. P., L. A. Malone, J. M. Collins, and S. B. Ruble. 2005. "Disability Type Influences Heart Rate Response during Power Wheelchair Sport." Medicine and Science in Sports and Exercise 37 (5): 718-723. doi:10.1249/01.MSS.0000161807.77552.8B 
Barfield, J. P., L. Newsome, and L. A. Malone. 2016. "Exercise Intensity during Power Wheelchair Soccer." Archives of Physical Medicine and Rehabilitation 97 (11): 1938-1944. doi:10.1016/ j.apmr.2016.05.012

Belo, A. Z. V. A., and M. I. B. de S. Mendes. 2017. "Être à la Plage Dans un Fauteuil : Un Nouveau Corps Propre.” Recherches E Éducations HS no. (1): 153-167.

Brymer, E., and R. Schweitzer. 2017. Phenomenology and the Extreme Sport Experience. New-York: Routledge.

Butler, J. 2006. Trouble Dans le Genre. Le Féminisme et la Subversion de L'identité. Paris: La Découverte.

Campbell,F.2009. Contours of Ableism:TheProductionofDisabilityand Abledness.London:Palgrave Macmillan.

Cottingham, M., J.Pate, and B. Gearity. 2015. “Examining 'Inspiration': Perspectives of Stakeholders Attending a Power Wheelchair Soccer Tournament." Canadian Journal of Disability 4 (1): 55-88.

Cottingham, M., M. Hums, M. Jeffress, D. Lee, and H. Richard. 2018. "Women of Power Soccer: Exploring Disability and Gender in the First Competitive Team Sport for Powerchair Users." Sport in Society 21 (11): 1817-1830. doi:10.1080:17430437.2017.1421174

Dyck, N., and E. Archetti. 2003. Sport, Dance and Embodied Identities. Oxford: Berg Publication.

Garland-Thomson. R. 2005. "Feminist Disability Studies.” Signs 30 (2): 1557-1587. doi:10. $1086 / 423352$

Garland-Thomson, R. 2013. “Disability Studies: A Field Emerged.” American Quarterly 65 (4): 915 926. doi:10.1353/aq.2013.0052

Giese, M., and S. Ruin. 2018. "Forgotten Bodies - An Examination of Physical Education from the Perspective of Ableism." Sport in Society 21 (1): 152-165. doi:10.1080/17430437.2016.1225857

Hockey, J., and J. A. Collinson. 2007. "Grasping the Phenomenology of Sporting Bodies."

International Review for the Sociology of Sport 42 (2): 115-131. doi:10.1177/1012690207084747

Howe, P.D. 2018. "Athlete, Anthropologist and Advocate: Moving towards a Lifeworld Where

Difference Is Celebrated." Sport in Society 21 (4): 678-688.

Howe, P.D., and C. F. Silva. 2017. "Challenging "Normalcy": Possibilities and Pitfalls of Paralympic Bodies." South African Journal for Research in Sport, Physical Education and Recreation 39 (1): 191-204.

Huang, C. J., and I. Brittain. 2006. "Negotiating Identities through Disability Sport." Sociology of Sport Journal 23 (4): 352-375. no

Jeffress, M. S. 2015. Communication, Sport and Disability: The Case of Power Soccer. London: Routledge.

Jeffress, M. S., and W.J. Brown. 2017. "Opportunities and Benefits for Powerchair Users through Power Soccer.” Adapted Physical Activity Quartely 34 (3): 235-255. doi:10.1123/apaq.2016-0022

Kumar, A., A. M. Karmarkar, D. M. Collins, A. Souza, M. L. Oyster, R. Cooper, and R. A. Cooper. 2012. "Pilot Study for Quantifying Driving Characteristics during Power Wheelchair Soccer." Journal of Rehabilitation Research and Development 49 (1): 75-82. doi:10.1682/JRRD.2010.09.0191

Lapointe, F. H. 1971. "The Phenomenal Body in the Later Writings of Merleau-Ponty." The Journal of General Psychology 84 (2): 251-265. doi:10.1080/00221309.1971.9711311

Leder, D. 1990. The Absent Body. Chicago: University of Chicago Press.

Marcellini, A. 2005. Des vies en fauteuil: Usages du sport dans les processus de déstigmatisation et d'intégration sociale. Paris: Éditions du CTNERHI.

Marcellini, A., E. De Léséleuc, and N. Le Roux. 2008. "Vivre en fauteuil roulant: Aspects symboliques". In Le Fauteuil Roulant, edited by Ravaud, J. F., Lofaso, F. \& Lepoutre, F. X., 123-133. Paris: Frison-Roche.

Mehta, N. 2011. "Mind-Body Dualism: A Critique from a Health Perspective." In Brain, Mind and Consciousness: An International, Interdisciplinary Perspective, edited by A. R. Singh, and S.A. Singh, 202-209. Mumbai: Mens Sana Research Foundation. doi:10.4103/0973-1229.77436

Merchant, S. 2011. "The Body and the Senses: Visual Methods, Videography and the Submarine Sensorium." Body \& Society 17 (1): 53-72. doi:10.1177/1357034X10394670

Merleau-Ponty, M. 1945. Phénoménologie de la Perception. Paris: Gallimard. 
Mouchet, A., K. Morgan, and G. Thomas. 2018. "Psychophenomenology and the Explicitation Interview for Accessing Subjective Lived Experience in Sport Coaching." Sport, Education and Society.1. Advance online publication. doi:10.1080/13573322.2018.1495189

Murphy, R. F. 1990. The Body Silent. London: W.W. Norton.

Nuss, M. 2011. L'identité de la Personne Handicapée. Paris: Dunod.

Orr, N., and C. Phoenix. 2015. "Photographing Physical Activity: Using Visual Methods to "Grasp at" the Sensual Experiences of the Ageing Body." Qualitative Research 15 (4): 454-472. doi:10.1177/1468794114543401

Pack, S., S. Kelly, and M. Arvinen-Barrow. 2017. "I Think I Became a Swimmer Rather than Just Someone with a Disability Swimming Up and Down:" Paralympic Athletes Perceptions of Self and Identity Development." Disability and Rehabilitation 39 (20): 2063-2070. doi:10.1080/09638 288.2016.1217074

Papadimitriou, C. 2008. "Becoming En-Wheeled: The Situated Accomplishment of Re-Embodiment as a Wheelchair User after Spinal Cord Injury." Disability \& Society 23 (7): 691-704. doi:10.1080/09687590802469420

Papadimitriou, C. 2012. "Phenomenologically-Informed Inquiry in Rehabilitation: How to Do Documentation and Interpretation of Qualitative Data." Physical Therapy Reviews 17 (6): 409416. doi:10.1179/1743288X12Y.0000000031

Parisot, A. S. 2010. "Le vécu du corps et l'intériorisation du regard. Une expérience personnelle." In Le Corps Vécu Chez la Personne Âgée et la Personne Handicapée, edited by P. Ancet, 139-152. Paris: Dunod.

Paterson, K., and B. Hughes. 1999. "Disability Studies and Phenomenology: The Carnal Politics of Everyday Life.” Disability \& Society 14 (5): 597-610. doi:10.1080/09687599925966

Pavey, A., N. Warren, and J. Allen-Collinson. 2015. "It Gives Me My Freedom": Technology and Responding to Bodily Limitations in Motor Neuron Disease.” Medical Anthropology 34 (5): 442 455. doi:10.1080/01459740.2015.1035782

Petitmengin, C. 2006. "Describing One's Subjective Experience in the Second Person: An Interview Method for the Science of Consciousness." Phenomenology and the Cognitive Sciences 5 (3-4): 229-269. doi:10.1007/s11097-006-9022-2

Richard, R., H. Joncheray, and E. Dugas. 2015. "Disabled Sportswomen and Gender Construction in Powerchair Football." International Review for the Sociology of Sport 52 (1): 61-81. doi:10.1177/1012690215577398

Richard, R. 2017. Être footballeur en fauteuil. Approche socio-phénoménologique du corps sportif en situation de handicap. Paris l'Harmattan.

Le Schipper, T., L. J. Lieberman, and B. Moody. 2017. "Kids like Me, We Go Lightly on the Head": Experiences of Children with a Visual Impairment on the Physical Self-Concept." British Journal of Visual Impairment 35 (1): 55-68.doi:10.1177/0264619616678651

Schilder, P. 1968. L'image du Corps. Etude Des Forces Constructives de la Psyché. Paris: Gallimard.

Senk, A. M. 2017. "Power (Wheelchair) Soccer". In Adaptative Sports Medicine: A Clinical Guide., edited by A. J. De Luigi, 149-159. Cham: Springer.

Seymour, W. 1998. Remaking the Body. Rehabilitation and Change. London: Routledge.

Shilling, C. 2016. "Body Pedagogics: Embodiment, Cognition and Cultural Transmission." Sociology 51 (6): 1205-1221. doi:10.1177/0038038516641868

Silva, C. F., and P.D. Howe. 2018. "The Social Empowerment of Difference: The Potential Influence of Para Sport." Physical Medicine and Rehabilitation Clinics of North America 29 (2): 397-408. doi:10.1016/j.pmr.2018.01.009

Smith, J. A., and M. Osborn. 2015. "Interpretative Phenomenological Analysis." In Qualitative Psychology: A Practical Guide to Research Methods., edited by J. A. Smith, 25-52. London: Sage.

Sparkes, A. C., and B. Smith. 2014. Qualitative Research Methods in Sport, Excercise and Healt. From Proces to Product. New York:Routledge.

Turner, B. S. 2001. "Disability and the Sociology of the Body." In Handbook of Disability Studies, edited by Albrecht, G. L., Seelman, K. D. and Bury, M., 252-266. London: Sage.

Vermersch, P. 2005. L'entretien D'explicitation. Paris: ESF éditeur. 
Vermersch, P. 2009. "Describing the Practice of Introspection." Journal of Consciousness Studies 16 (10-12): 20-57.

Watson, N., and B. Woods. 2005. "No Wheelchairs beyond This Point: A Historical Examination of Wheelchair Access in the Twentieth Century in Britain and America." Social Policy and Society 4 (1): 97-105. doi:10.1017/S1474746404002222

Watson, N., and B. Woods. 2008. A Social and Technological History of the Wheelchair. In Le Fauteuil Roulant, edited by Ravaud, J. F., Lofaso, F. and Lepoutre, F. X., 9-20. Paris: Frison-Roche.

Warnier, J. P. 1999. Construire la Culture Matérielle. L'homme Qui Pensait Avec Ses Doigts.Paris: Presses universitaires de France.

Wessel, R. D., J. Wentz, and L. L. Markle. 2011. "Power Soccer: Experiences of Students Using Power Wheelchairs in a Collegiate Athletic Club." Journal of Postsecondary Education and Disability 24 (2): 147-159.

Winance, M. 2000. “De L'ajustement Entre Les Prothèses et Les Personnes: Interactions et Transformations Mutuelles." Handicap, Revue de Sciences Humaines et Sociales 85: 11-26.

Winance, M. 2006. "Trying out the Wheelchair: The Mutual Shaping of People and Devices through Adjustment." Science, Technology E Human Values31 (1):52-72. doi:10.1177/0162243905280023

Zeiler, K. 2010. "A Phenomenological Analysis of Bodily Self-Awareness in the Experience of Pain and Pleasure: On Dys-Appearance and eu-Appearance." Medicine, Health Care, and Philosophy 13 (4): 333-342. doi:10.1007/s11019-010-9237-4

Zitzelsberger, H. 2005. “(In)Visibility: Accounts of Embodiment of Women with Physical Disabilities and Differences.” Disability \& Society 20 (4): 389-403. 